\title{
Characterization of Rice Husk and Coconut Shell Briquette as an Alternative Solid Fuel
}

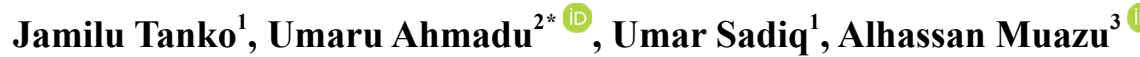 \\ ${ }^{1}$ Department of Physics, Ahmadu Bello University, Zaria, Nigeria \\ ${ }^{2}$ Department of Physics, Federal University of Technology, P.M.B., 65, Minna, Nigeria \\ ${ }^{3}$ Department of Physics, Federal College of Education (Tech.), Bichi, Kano State, Nigeria \\ E-mail: u.ahmadu@yahoo.com
}

Received: 24 August 2020; Revised: 28 September 2020; Accepted: 7 November 2020

\begin{abstract}
The physical properties of briquettes made from rice husk and coconut shell in different ratios were evaluated based on their thermo-physical properties. The calculated calorific values of the rice husk and coconut shell are $16.51 \mathrm{MJ} / \mathrm{kg}$ and $18.60 \mathrm{MJ} / \mathrm{kg}$, with densities of $1.50 \mathrm{~g} / \mathrm{cm}^{3}$ and $3.00 \mathrm{~g} / \mathrm{cm}^{3}$, respectively. Coconut shell has lower moisture and ash content of $10 \%$ and $26 \%$, respectively, before briquetting. Comparisons of the experimental and calculated calorific values of the briquettes (17 to $21 \mathrm{MJ} / \mathrm{kg}$ ) showed that they are in agreement with those of the American Standard of Testing Materials (ASTM) and those reported in the literature. The results further showed that the calorific values of the five briquette ratios were not a function of their moisture and ash contents, rather their total carbon contents. The briquette at the ratio 90:10 of rice husk to coconut shell has the highest calorific value and implies that it has more heating advantages and will therefore be suitable as an alternative solid fuel.
\end{abstract}

Keywords: rice husk, coconut shell, briquette, calorific value

\section{Introduction}

Agricultural wastes are the residues from the growing and processing of raw agricultural products [1]. These wastes will constitute a nuisance to the environment if not properly managed. The agricultural concern here is the crop wastes (corn stalks, sugarcane bagasse, drops, and culls from fruits and vegetables, prunings). These agro-residues have been mostly used for heating applications in many homes for decades. But their high moisture contents and low densities make them unsuitable for direct use as fuel due to combustion and handling problems. The potential agro-residues which do not pose collection and drying problems related to biomass are rice husk, groundnut shell, coffee husk, and coconut shell.

The outer coverings of rice and coconut are known as rice husk (RH) and coconut shell (CS), respectively. RH and $\mathrm{CS}$ are the foremost low cost and low-density materials obtainable in large quantities as solid waste bye-products. They are also low cost and attractive to current cooking methods which substitute conventional cooking fuel. By utilizing our abundant agricultural residues, households can scale back the quantity of firewood, charcoal, and fossil fuel burned with a resultant increase in household income, air quality, reduction of firewood collection burden on women, and greenhouse gas emissions. These agricultural waste products can be properly recycled into useful products, thereby increasing the

Copyright (C)2020 Umaru Ahmadu, et al.

DOI: https://doi.org/10.37256/aecm.212021608

This is an open-access article distributed under a CC BY license

(Creative Commons Attribution 4.0 International License)

https://creativecommons.org/licenses/by/4.0/ 
energy resource mix and reducing the environmental pollution. The decreasing availability of fuel wood, as well as the ever-rising cost of hydrocarbon oil and cooking gas in Nigeria, has drawn attention to the necessity to contemplate different sources of energy for domestic and industrial use within the country. The decision of the Nigerian government to close the country's land borders has resulted in increased local rice production. The volume of rice produced locally has soared to eight million metric tons with the aim of attaining 18 million tons by 2023 [2]. Rice husk accounts for 20$30 \%$ of the total weight of rice produced [3]. Another potential of waste that can be utilized as additional raw material in briquette production is CS. CS biomass was initially considered as waste from its fruit production but nowadays has been wielded as a raw material in the process of activated charcoal-making. As to 2016, Nigeria produced 283,774 Mt of coconut which increased to $288,615 \mathrm{Mt}$ in 2018 [4]. The calorific value of the coconut shell is $20890 \mathrm{~kJ} / \mathrm{kg}$, which still revolves around the low biomass calorific value range [5].

Biomass is one promising renewable energy resource that can be used directly or indirectly [6]. The incomplete combustion of biomass can produce $\mathrm{CO}, \mathrm{SO}_{2}, \mathrm{NO}_{2}$, fluorine, suspended particulate matter, and other harmful products within the home. These compounds are often many times more concentrated than recommended health standards and may exceed pollution levels of the most polluted industrial cities. Additionally, intensive fuel wood and charcoal production contribute to ecological deterioration once unsustainably harvested. Biomass briquette developed from agricultural waste alleviate the troubles and could be a potential supply of renewable energy due to the sustainability of the resource, positive impact on the surroundings, reduced transportation, collection, and storage costs. There have been reports on briquetting of non-pretreated agricultural wastes through an extrusion and carbonized biomass which is generally converted to a briquette form. Also, sawdust, rice husk, cotton stalk, and hazelnut shell charcoal [7] have been experimentally studied. Some reports [8] indicate that mechanical and physical properties of the charcoal briquette are influenced by many parameters, such as die pressure, dwell time, charcoal particle size, and binder type.

Both RH and CS exhibit superior physical and mechanical properties that can be utilized more effectively in the development of composite materials for various applications. The calorific value of RH is $13807.2 \mathrm{~kJ} / \mathrm{kg}$ [9] while that of CS is still low, thereby engendering the need for a method to increase the calorific value of both RH and CS. Their calorific values could be created by making briquettes from the mix of the two as the main ingredients. The process of fabricating the briquettes is by pyrolysis of rice husk and coconut shell at temperatures of 400 to $450^{\circ} \mathrm{C}$. Thus the pyrolysis can create top-notch charcoal so that the briquettes can have high calorific values.

In the current work, a briquette has been developed from RH and CS. The physical, proximate, and ultimate analysis of the briquettes were carried out. This is expected to be alternative energy that will replace costly fossil fuel and result in good biomass fuels that can meet the standard criteria of briquettes formation for efficient burning to release sufficient heat energy as fuel for domestic and industrial purposes.

\section{Experimental procedure}

The materials used in this work were RH, CS, and binder (cormart starch). The RH and CS were obtained locally from Dariya Rice processing mill Kakuri and Railway Station Market, Kaduna State, Nigeria. An investigation carried out revealed that approximately 11.5 tons of rice were ground every day in the Kakuri market, which gave the insight that abundant rice husks are in the area. The sampled RH and CS were cleaned and dried under the sun for about 3 to 4 days in order to reduce the moisture content as well as physical contaminants such as dirt, dust, and mud. A Cormart renewal starch was used with ordinary water. It is a starch that is commonly used in most Nigerian households. It is modified starch with fragrance produced by CORMART (NIGERIA) Limited, Lagos, Nigeria.

The experimental steps involved in the briquette fabrication have been described in the sections described below. These include carbonization, briquettes fabrication and characterization. $\mathrm{RH}$ and CS were fed to a retort with $5 \mathrm{~kg}$ capacity. The RH and CS were carbonized at temperature $450^{\circ} \mathrm{C}$ for $4 \mathrm{~h}$ in a furnace in order to produce charcoal. The fully carbonized material was collected for further processing. The carbonized RH and CS charcoals were crushed with a blender to smaller particles and sieved using ASTM Standard with a 710-micrometre mesh to obtain uniformity in the particle sizes. Thereafter, the samples were properly mixed at the nominal mass mixing ratios of rice husk-coconut shell: 50:50, 60:40, 70:30, 80:20, and 90:10. Thereafter, the Cormart starch was used as a binder and added to each component of the mixture. The final mixture was poured into the dough and stirred until fully blended. Table 1 shows a summary of 
the mass ratios (\%) used for the experiment.

Table 1. Rice husk and coconut shell charcoal briquettes nominal compositions

\begin{tabular}{cccccccc}
\hline $\mathrm{S} / \mathrm{N}$ & 1 & 2 & 3 & 4 & 5 & 6 & 7 \\
\hline Rice Husk (RH) (\%) & 100 & 0 & 50 & 60 & 70 & 80 & 90 \\
Coconut Shell (CS) (\%) & 0 & 100 & 50 & 40 & 30 & 20 & 10 \\
\hline
\end{tabular}

The briquettes were fabricated by setting up the dough into a cylindrical mould with a dimension of $2 \mathrm{~cm}$ by $2 \mathrm{~cm}$. They were subsequently briquetted at room temperature in a hydraulic-powered printing machine. The briquettes were placed in a tray and sun-dried for 4 days. The dried briquettes were packed in a tightly closed plastic bag to keep them dry. The flow chart of the sample preparation process is shown in Figure 1.

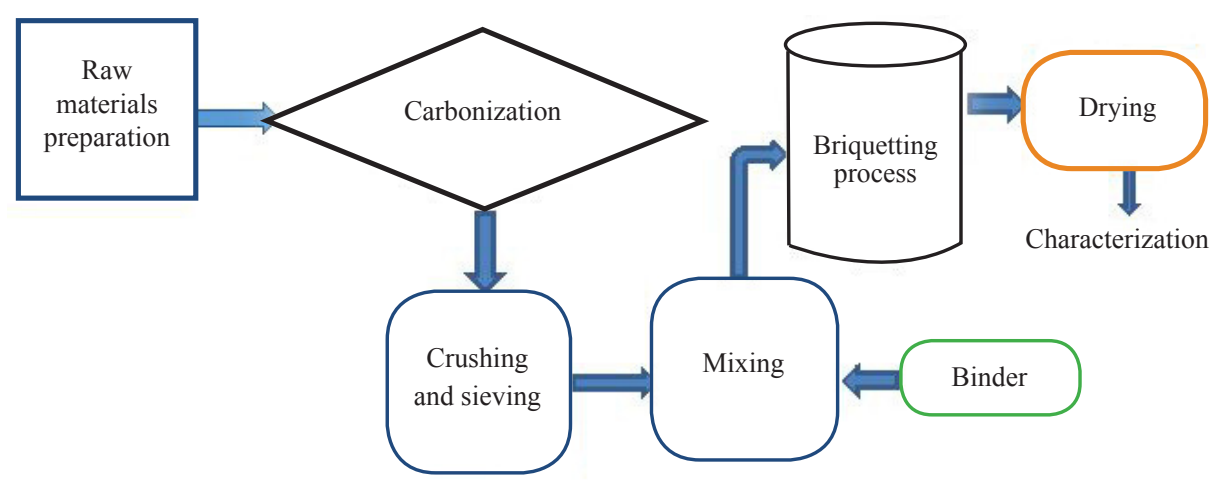

Figure 1. Flow chart for the sample preparation

\subsection{Characterization}

Characterization of briquettes was conducted using physical, proximate, and calorific value test, Fourier Transform Infrared (FTIR) spectrometry. The instrumentation used include Bomb calorimeter (6100 Compensate Calorimeter, U.S.A.), graduated cylinder, hydraulic compression, hot plate, thermometer, Shimadzu-8400s FTIR Spectrophotometer (Japan), oven with the crucible, digital balance, 710-micrometre mesh sieve, retort and blender.

\subsubsection{Moisture content determination}

The process involved the determination of the water content of the material by drying the sample to a constant mass at a specified temperature. A Qlink oven model QOT, no. LB049A02-01, rated voltage $230 \mathrm{~V}$ with a power of $1200 \mathrm{~W}$ at frequency $50 \mathrm{~Hz}$ was used to maintain the temperature of $110 \pm 5^{\circ} \mathrm{C}$. A balance with a sensitivity of up to $0.1 \%$ of the mass of the test sample, and with a capacity equal to, or greater than the wet mass of the sample to be tested was used for the measurements. A specific quantity of the moist sample based on the maximum particle size was weighed and recorded as "wet weight of sample", and then placed in a crucible of known mass and then transferred to an oven for drying. The drying process was maintained until a constant mass was attained at a temperature of $110 \pm 5^{\circ} \mathrm{C}$ after which the sample was brought out and allowed to cool. The weight of the cooled sample was subsequently recorded immediately as "dry weight of sample". The moisture content was calculated using Eqn. (1) [10]:

$$
\text { Moisture content }=\frac{\text { initial weight of the sample }- \text { oven-dried weight of the sample }}{\text { oven-dried weight of the sample }} \times 100 \%
$$




\subsubsection{Ash content}

The samples were weighed in a ceramic crucible and placed in an electric muffle furnace. As alkali oxides are volatile at high temperatures, the temperature was kept at $550^{\circ} \mathrm{C}$ for all the samples for $3 \mathrm{~h}$. The sample was removed from the furnace and the ceramic crucible was allowed to cool. The crucible containing the ash was weighed and the ash content of each sample was determined by the difference between the crucible before and after heating. The percentage quantity of ash was determined by the formula given in Eqn. (2) [11]:

$$
\text { Ash content }=\frac{w_{3}-w_{1}}{w_{2}} \times 100 \%
$$

where $\mathrm{w}_{1}=$ initial weight of the empty crucible

$\mathrm{w}_{2}=$ sample weight

$\mathrm{w}_{3}=$ final weight of the sample and crucible.

\subsubsection{Calorific value}

The total heat released by the briquette when complete combustion occurred is called the calorific value. The direct determination of calorific values was determined using a Parr Oxygen bomb calorimeter (Parr instrument company, 6100 Calorimeter, U.S.A.) as shown in Figure $2.1 \mathrm{~g}$ of the sample was weighed using a digital balance. The sample was charged into an oxygen bomb vessel in which the combustible charges can be burnt. The connecting tube that supplied the oxygen was removed and the bomb calorimeter containing the oxygen with the sample was connected with an electrode to provide ignition current to a fuse wire which was submerged into a bucket containing water of about 2 litres in the calorimeter. An electrode was connected directly onto the vessel while the bomb and the bucket were held into the calorimeter jacket to serve as a thermal shield as shown in Figure 2. The setup was allowed to warm for a period of about 6 to $7 \mathrm{~min}$ for the combustion to take place. The calorific values of the samples were calculated by using Eqn. (3):

$$
\mathrm{HCV}=\left(M_{1} M_{2}\right) X\left(T_{c}+T_{1}-T_{2}\right) X C_{w} / M_{f}+2.6
$$

where $M_{1}$ and $M_{2}$ are mass of water in the copper calorimeter and water equivalent of a bomb calorimeter, respectively. $M_{f}$ is the mass of the fuel sample whose calorific value is to be determined. $T_{1}$ and $T_{2}$ are the final and initial temperatures of the water sample. $T_{c}$ is temperature correction for radiation losses, $C_{w}$ is the specific heat capacity of water. The result can be displayed in either unit of $\mathrm{MJ} / \mathrm{kg}$ or $\mathrm{Cal} / \mathrm{g}$. This procedure was repeated for all the samples.

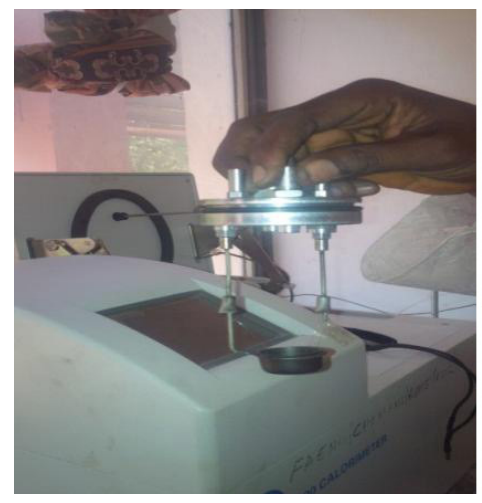

(a)

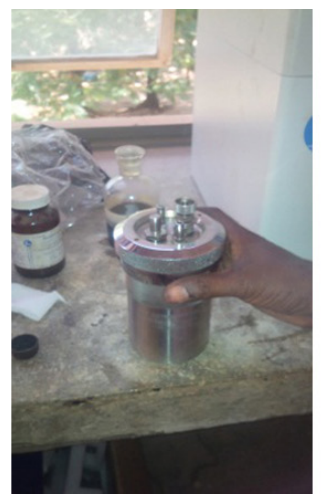

(b)

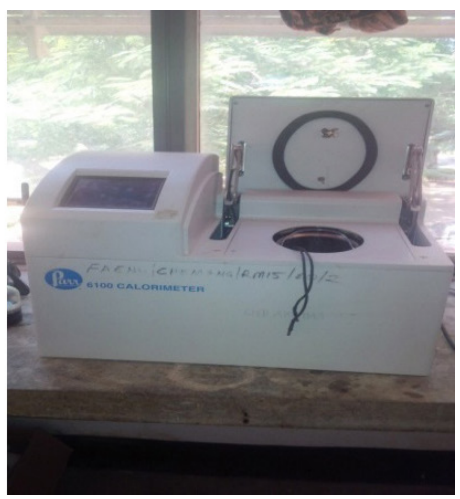

(c)

Figure 2. (a) Crucible with electrodes connected to fuse where combustion takes place in the bomb; (b) the bomb where the crucible and electrodes which are in contact with the fuse are situated (c) the bomb calorimeter contains a thick-walled cylindrical vessel and consists of the lid which support two electrodes that are in contact with the fuse and fuel samples of known weight 


\subsubsection{Density measurement}

The density was measured using Archimede's principle. The mass of the sample was measured and recorded with a mass balance. Water was added into a graduated cylinder with the volume marking recorded as $\mathrm{V}_{1}$. The fine powder of the sample was added to the water in the cylinder and the new volume was recorded as $\mathrm{V}_{2}$. The difference between the initial $\left(\mathrm{V}_{1}\right)$ and final volumes $\left(\mathrm{V}_{2}\right)$ is the volume of the sample. To get the density $\rho$ of the sample, the measured mass of the sample was divided by this volume difference. This is represented by Eqn. (4):

$$
\rho=\frac{\text { mass of the sample }}{\text { actual volume }}=\frac{m}{v}
$$

\subsubsection{Fourier Transform Infrared (FTIR) spectrometry}

Infra-red spectral analysis of the samples was performed using FTIR-8400S Fourier transform infra-red spectrophotometer (Shimadzu, Japan) to identify the surface functional groups and fingerprints of the components of the sample from the obtained spectrum. The sample was scanned with infrared radiation in the wavenumber range $4000 \mathrm{~cm}^{-1}$ to $400 \mathrm{~cm}^{-1}$ to obtain the spectrum.

\section{Results and discussion}

\subsection{Briquettes properties}

The RH, CS, and five different ratios of briquettes with compositions (RH: CS) of 50:50, 60:40, 70:30, 80:20, and 90:10 were produced. The samples were analyzed for ash content with reference to ASTM D-3174, moisture content with reference to ASTM D-3174 and calorific value with reference to ASTM D-2015, and density. Table 2 shows the results of the physical properties of the briquettes produced.

Table 2. Physical properties of briquettes

\begin{tabular}{|c|c|c|c|c|c|c|}
\hline S/No & Sample ID & $\begin{array}{l}\text { Sample weight } \\
(\mathrm{g})\end{array}$ & $\begin{array}{l}\text { Calorific value } \\
(\mathrm{MJ} / \mathrm{kg})\end{array}$ & $\begin{array}{l}\text { Moisture content } \\
(\%)\end{array}$ & $\begin{array}{c}\text { Ash content } \\
(\%)\end{array}$ & $\begin{array}{r}\text { Density } \\
\left(\mathrm{g} / \mathrm{cm}^{3}\right)\end{array}$ \\
\hline 1 & $\mathrm{RH}$ & 0.5 & 16.5101 & 16 & 38 & 1.50 \\
\hline 2 & $\mathrm{CS}$ & 0.5 & 18.6011 & 10 & 26 & 3.00 \\
\hline 3 & $50: 50$ & 0.5 & 14.7715 & 12 & 31 & 1.50 \\
\hline 6 & $80: 20$ & 0.5 & 15.4181 & 10 & 33 & 3.00 \\
\hline 7 & $90: 10$ & 0.5 & 17.8543 & 14 & 32 & 3.00 \\
\hline
\end{tabular}

\subsection{Moisture content}

The moisture content of each briquette is shown in Figure 2. It shows that the moisture content of RH is $16 \%$, which is higher than the value of $12.6 \%$ reported by other researchers [12], and in excess of the limit of $15 \%$ recommended for briquetting of agro-residues [13], while the CS briquette has 10\%. The moisture contents of 50:50, 60:40, 70:30, 80:20, and 90:10, RH and CS are in the range of 10 to $14 \%$. The difference in moisture contents in 50:50, $60: 40,70: 30,80: 20$, and 90:10 briquettes can be attributed to the unequal composition of the RH and CS charcoal mixture. The results show that the moisture contents of CS and 60:40, 70:30, 80:20 have the same value of 10\%, which is $1 \%$ higher than that reported [14]. The lower moisture content of $10 \%$ is attributed to increased RH content in the mixture. These results are in agreement with recommendations of 5-10\% moisture content for good quality briquettes [15] 
and indicate that the briquettes are appropriate for utilization as an alternative energy source. Figure 3 is a summary of the comparison of the briquettes in terms of their moisture contents using a bar chart.

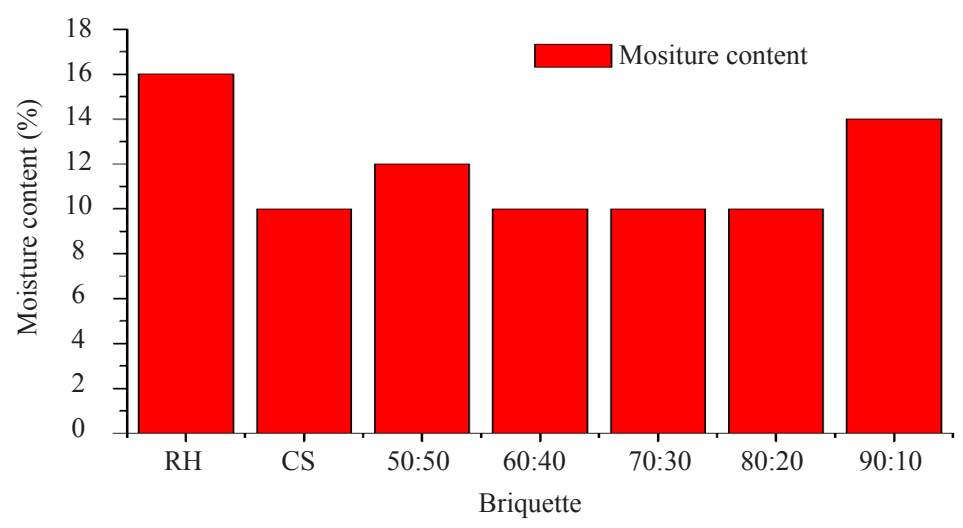

Figure 3. Bar chart of moisture content of mixed charcoal briquettes

\subsection{Ash content}

Figure 4 shows the ash contents of different mixed charcoal briquettes with their various mixing ratios. The values of the ash contents ranged from 26-38\%, with RH and CS briquettes having the highest and lowest ash contents of 38 and $26 \%$, respectively. In another study, the highest ash content was reported in a composite briquette of $100 \%$ rice husk [16]. The 60:40 sample exhibited the highest ash content of $36 \%$ while the $70: 30$ had the lowest ash content of $27 \%$, amongst the compositions of RH and CS briquettes. The unequal composition of RH and CS contents resulted in the variation of the ash contents in the briquettes. It can be observed from Figure 4 that the higher the ash contents the lower the calorific values of the briquettes. CS with ash content of $26 \%$ has a higher calorific value of $18.6 \mathrm{MJ} / \mathrm{kg}$. Ash content is inversely proportional to calorific value [17]. Ash is an incombustible material that will partake in the chemical reaction in the combustion process.

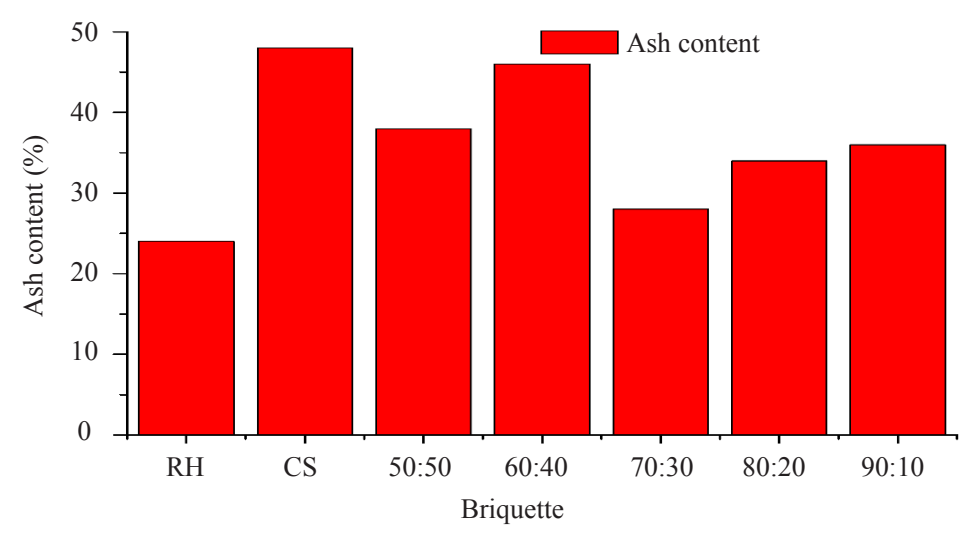

Figure 4. Bar chart of Ash content of different mixed charcoal briquettes

\subsection{Calorific value}

The calorific values of RH, CS, and different mixed charcoal briquettes with various mixing ratios are shown in Figure 5. The calorific values are in the range 14 to $7 \mathrm{MJ} / \mathrm{kg}$ with $\mathrm{CS}$ and 90:10 briquettes having the highest and 
lowest calorific values of $18.6011 \mathrm{MJ} / \mathrm{kg}$ and $14.7715 \mathrm{MJ} / \mathrm{kg}$, respectively. CS's calorific value is higher than $13.0 \mathrm{MJ} / \mathrm{kg}$ reported by some workers [18]. The calculated calorific values compared well with those of the American Standard of Testing Materials (ASTM) and those that have been widely reported in the literature which is in the range 17 to $21 \mathrm{MJ} / \mathrm{kg}$ [19]. The results also compare well with the data reported [19] using elephant grass and spear grass samples. However, the result obtained for 50:50 and 80:20 are lower than those of $20.7 \mathrm{MJ} / \mathrm{kg}$ and $17.3 \mathrm{MJ} / \mathrm{kg}$ for the same composition reported in the literature [20]. It was also observed that the briquettes at 60:40 and 90:10 have higher calorific values when compared with those that have been widely reported which are in the range 17 to $21 \mathrm{MJ} / \mathrm{kg}$ for biomass materials. These imply that they have more heating advantages and will be suitable for alternative solid fuel.

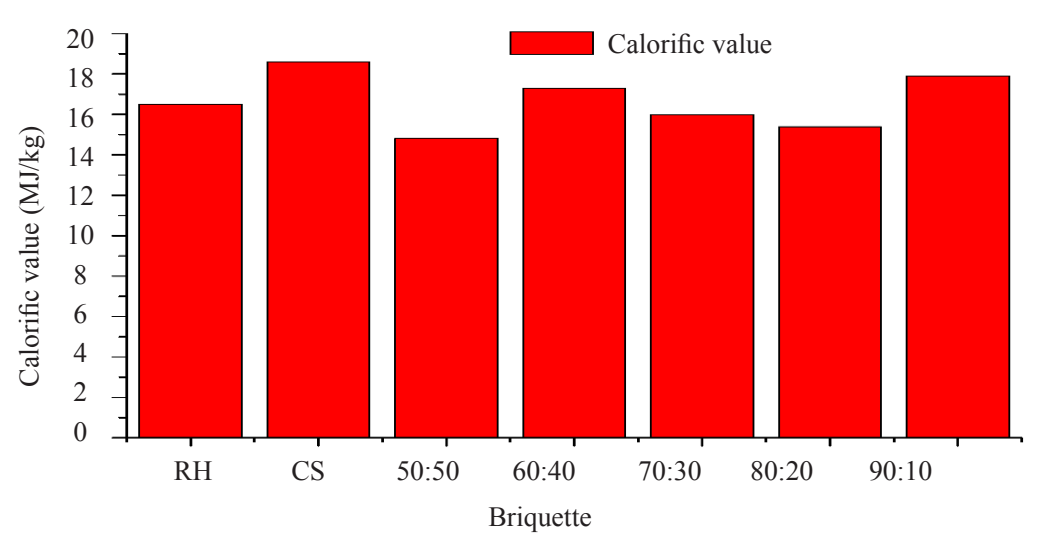

Figure 5. Bar chart of calorific value of different mixed charcoal briquettes

\subsection{Density measurements}

The physical properties of the RH, CS, and mixed charcoal briquettes were measured using the density. The actual and measured densities of the samples are presented in Table 3 while the bar chart is depicted in Figure 6 . The measured density ranged from $1.5 \mathrm{~g} / \mathrm{cm}^{3}$ to $3.0 \mathrm{~g} / \mathrm{cm}^{3}$ and shows that CS is the densest, and in theory, ought to have the highest energy content. The RH density of $1.5 \mathrm{~g} / \mathrm{cm}^{3}$ is greater than that of $0.678 \mathrm{~g} / \mathrm{cm}^{3}$ reported in the literature [20]. On the other hand, RH and the briquettes prepared at 50:50 are the lowest and hence have low energy contents. The density of a material varies with temperature and pressure, which is typically small for solids and liquids but larger for gases. Increasing the pressure on an object decreases the volume of the object and increases its density. But increasing the temperature of a substance (generally) decreases its density by increasing its volume. These account for the reason why low-density biomass briquettes usually have low energy densities. However, the low energy density of an RH briquette is equally enhanced by mixing it with CS which has a higher density than the RH. Some workers [21] reported an average density of CS:RH briquettes mixture ratio of $50: 50$ and $80: 20$ as 0.81 and $0.77 \mathrm{~g} / \mathrm{cm}^{3}$, respectively, which are comparatively lower than the values obtained in the present work. It is observed that the density at the ratio 90:10 is the same as the pristine CS value; this is partly due to the high density of CS, comparatively. 
Table 3. Density of the briquette of different mass ratios

\begin{tabular}{ccccc}
\hline S/No & Sample ID & Sample weight $(\mathrm{g})$ & Sample volume $\left(\mathrm{cm}^{3}\right)$ & Density $\left(\mathrm{g} / \mathrm{cm}^{3}\right)$ \\
\hline 1 & Rice husk & 3.00 & 2.00 & 1.50 \\
2 & Coconut shell & 3.00 & 1.00 & 3.00 \\
3 & $50: 50$ & 3.00 & 2.00 & 1.50 \\
4 & $60: 40$ & 3.00 & 1.50 & 2.00 \\
5 & $70: 30$ & 3.00 & 1.50 & 2.00 \\
6 & $80: 20$ & 3.00 & 1.00 & 3.00 \\
7 & $90: 10$ & 3.00 & 1.00 & 3.00 \\
\hline
\end{tabular}

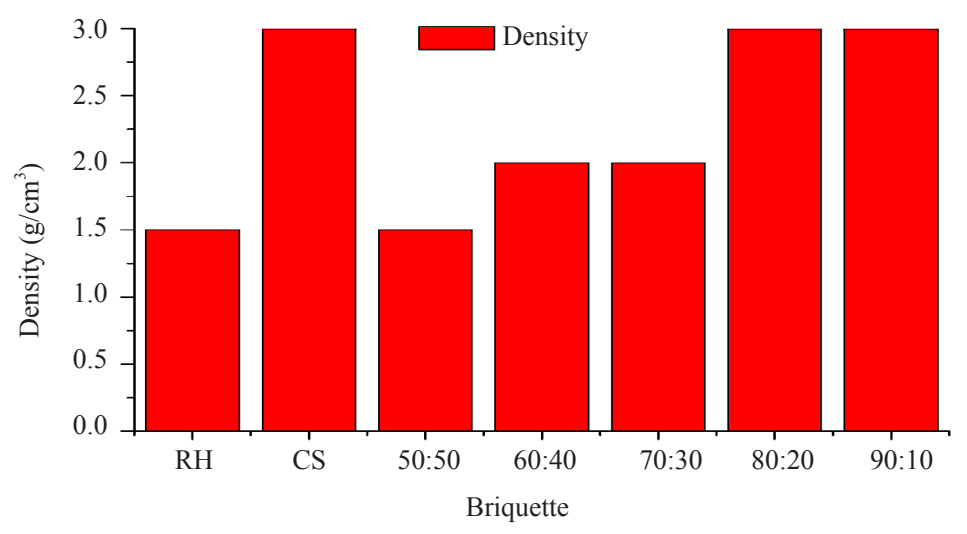

Figure 6. Bar chart of density profile of different mixed charcoal briquettes

\subsection{Fourier transform infrared spectroscopy}

The FTIR spectra of CS and RH are shown in Figures 7 and 8, respectively. The main composition of CS consists of alcohol, amides, carboxylic acid, alkenes, alkyl halides, and ethers. These organic materials contain functional groups such as O-H, N-H, C, C O, C-F, C-O, C-O-C, and C-I (Table 4). According to Figure 7, the band at $3399.65 \mathrm{~cm}^{-1}$ indicates the presence of stretching and symmetric stretching vibration of $\mathrm{O}-\mathrm{H}$ and $\mathrm{N}-\mathrm{H}$ for alcohols, carboxylic acid, and amides, respectively [22] and points to dehydration of cellulose and lignin components. The bands at $2932.86 \mathrm{~cm}^{-1}$

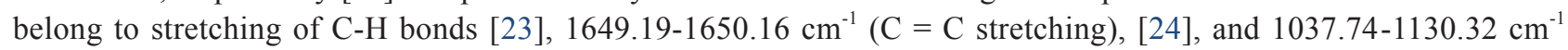
(C-O-C asymmetry stretching). The peak at $678.00 \mathrm{~cm}^{-1}$ is assigned to the bending vibration of the $\mathrm{C}-\mathrm{H}$ bond [25], while the further drop in the band to $406.03-417.60 \mathrm{~cm}^{-1}$ (C-I stretching) indicated the involvement of alkyl halides with $\mathrm{C}^{-\mathrm{I}}$ stretching vibration as observed by other workers [26]. The shift in absorption bands of the functional groups in the RH and CS samples showed that the chemical activation of the charcoal occurred. 


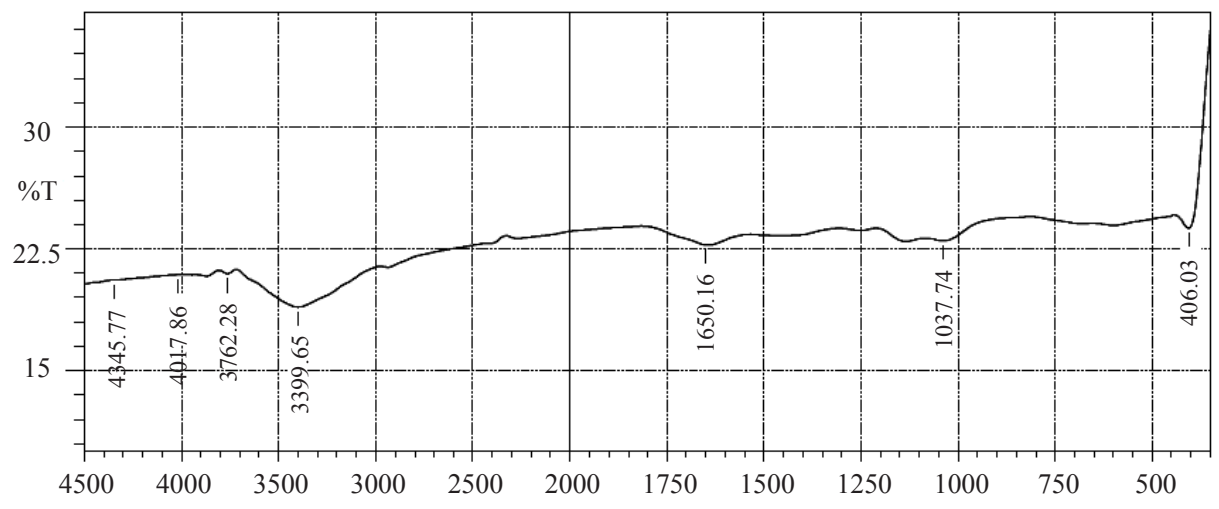

Figure 7. FTIR spectra of CS showing the different bands of transmission

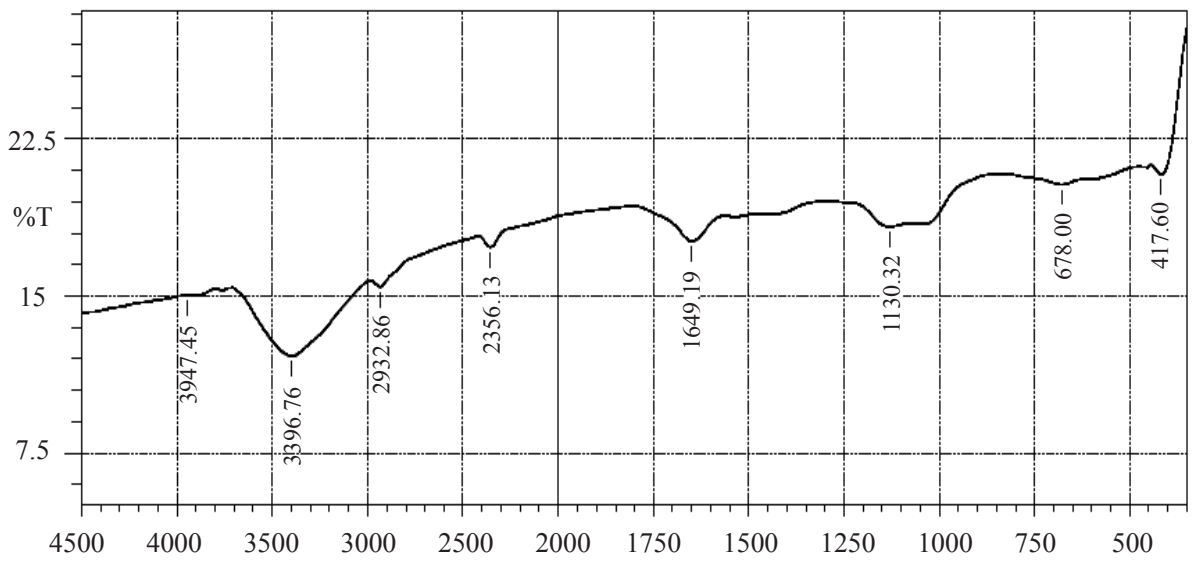

Figure 8. FTIR spectra of RH showing the different bands of transmission

Table 4. FTIR spectra assignment on stretching and bending of the functional groups for CS

\begin{tabular}{|c|c|c|c|}
\hline Functional groups & $\begin{array}{c}\text { Wavenumber } \\
\mathrm{cm}^{-1}\end{array}$ & Assignment and mode of vibration & Intensity \\
\hline Alcohols & 3399.65 & O-H stretching & $\mathrm{s}$, broad \\
\hline \multirow[t]{2}{*}{ Amides } & & $\begin{array}{l}\mathrm{N}-\mathrm{H} \text { symmetric and } \\
\text { asymmetric stretching }\end{array}$ & $\mathrm{w}-\mathrm{m}$ \\
\hline & & $\mathrm{O}-\mathrm{H}$ stretching & \\
\hline Carboxylic acid & & & $\mathrm{s}$, broad \\
\hline Alkenes & 1650.16 & $\mathrm{C}=\mathrm{C}$ stretching & vw-m \\
\hline \multirow[t]{2}{*}{ Amides } & & $\mathrm{C}=\mathrm{O}$ stretching & m-s, s, broad \\
\hline & & $\mathrm{N}-\mathrm{H}$ bending & m-s \\
\hline Alkyl halides & 1037.74 & C-F stretching & Vs \\
\hline Alcohols & & $\mathrm{C}-\mathrm{O}$ stretching & $\mathrm{m}-\mathrm{s}$ \\
\hline Ethers & & $\begin{array}{l}=\mathrm{C}-\mathrm{O}-\mathrm{C} \text { symmetric and } \\
\text { asymmetric stretching }\end{array}$ & $\mathrm{m}-\mathrm{s}$ \\
\hline Alkyl halides & 406.03 & C-I stretching & $\mathrm{S}$ \\
\hline
\end{tabular}


Table 5. FTIR spectra assignment on stretching and bending of the functional groups for RH

\begin{tabular}{cccc}
\hline Functional groups & $\begin{array}{c}\text { Wavenumber } \\
\mathrm{cm}^{-1}\end{array}$ & Assignment and mode of vibration & Intensity \\
\hline Alcohols & 3396.76 & O-H stretching & s, broad \\
Amides & & N-H symmetric stretching & w-m \\
Alkanes and alkyls & 2932.86 & C-H stretching & S \\
Alkenes & 1649.19 & C-C stretching & broad, m-s \\
Amides & & C-O stretching & m-s \\
Alcohols & 1130.32 & C-O stretching & s, broad \\
Alkynes & 678.00 & EC-H bending & S \\
Alkyl halides & 417.60 & C-I stretching &
\end{tabular}

\subsection{Relationship between calorific value, moisture and ash contents of the samples}

The results obtained for the calorific value, moisture, and ash contents of the samples are shown in Figure 9. It was found that RH and CS have calorific values of $16.51 \mathrm{MJ} / \mathrm{kg}$, and $18.6011 \mathrm{MJ} / \mathrm{kg}$, moisture contents of $16 \%$, and $10 \%$ ash contents of $38 \%$ and $26 \%$, respectively, before briquetting. The experimental results show that the calorific values ranged from $14.77 \mathrm{MJ} / \mathrm{kg}$ to $17.85 \mathrm{MJ} / \mathrm{kg}$, moisture contents ranged from $10 \%$ to $14 \%$ and the ash contents from $27 \%$ to $36 \%$, respectively, after briquetting. The results obtained for the experimental and calculated calorific values before and after briquetting of the samples are in good agreement. The experiments were performed using five different briquette ratios at a constant mesh size of $710 \mu \mathrm{m}$. Comparison between the calorific value, moisture and ash contents of the RH and CS are presented in Figure 9. It is evident that the calorific value of the sample is not linearly dependent on the moisture and ash contents, rather, it is directly related to their total carbon contents, i.e., the higher the carbon content of plant biomass the higher the heat energy to do useful work [19]. Some workers [23] reported a calorific value of $19.951 \mathrm{~kJ} / \mathrm{kg}$ for a combination of $50 \%$ coconut shell (25\%) corn cob (25\%) sugarcane bagasse, compared to coconut shell charcoal's $21.693 \mathrm{~kJ} / \mathrm{kg}$. Other workers [24] reported ash and coconut moisture contents of $10.37 \%$ and $1.56 \%$, respectively; while rice husks show ash and moisture contents of $15.63 \%$ and $7.38 \%$, respectively. The fixed carbon content represents the combustible material present in the charcoal residue after the loss of moisture and volatile matter. Carbon and Oxygen contents are important in biomass energy analysis. High oxygen content tends to lower calorific value while high carbon content tends to form high-grade biomass fuel [19].

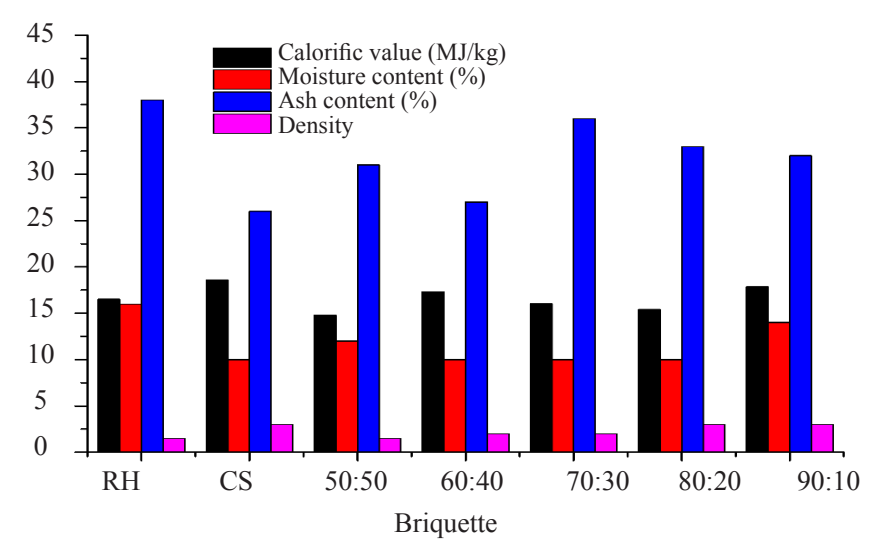

Figure 9. A chart of calorific value, moisture and ash contents of the samples with different mixtures of rice husk and coconut shell 


\section{Conclusion}

In this work, the briquettes of $\mathrm{RH}, \mathrm{CS}$ and their respective mixture ratios were fabricated and proximate tests, calorific energy values, density measurements, and Fourier Transform Infrared Spectroscopy (FTIR) analyses were investigated. It was found that the CS has the highest calorific value, low moisture and ash contents. Similarly, it was observed that RH and CS mixtures and the briquettes at 60:40 and 90:10 of RH to CS ratios had enhanced calorific values. These results compare well with those of the American Standard of Testing Materials (ASTM) and those reported in the literature in the acceptable range of 17 to $21 \mathrm{MJ} / \mathrm{kg}$ and imply that they have more heating advantages and more competitive compared to conventional solid fuels. Further, the results showed that the calorific values of the five briquette ratios were not a function of their moisture and ash contents, rather their total carbon contents. The chemical compositions of the briquette samples via various peak frequencies of functional groups were confirmed by the FTIR analysis.

\section{References}

[1] Obi FO, Ugwuishiwu BO, Nwakaire JN. Agricultural waste concept, generation, utilization and management. Nigerian Journal of Technology (NIJOTECH). 2016; 35(4): 957-964. Available from: DOI: 10.4314/njt.v35i4.34.

[2] Chibuzor O. Strengthening local rice production. Thisday Newspaper. Available from: https://www.thisdaylive. com/index.php/2020/01/30/strengthening-local-rice-production/ [Accessed 15th October 2020].

[3] Maulida SD, Bukhori F. Effect of rice husk waste and rice husk ash composition as filler in plastic bottle drink waste composites on water absorption properties. International Journal of Science and Research. 2015; 4(6): 21462148.

[4] Sanwo-Olu. Volume of coconut production in Lagos hits N10bn. PM News Nigeria. Available from: https://nipc. gov.ng/2019/10/31/volume-of-coconut-production-in-lagos-hits-n10bn/ [Accessed 22th October 2020].

[5] Suhartono, Gasela F, Khoirunnisa A, Suharto. An evaluation of a solid biomass cook stove in small household industry. Journal of Physics: Conference Series. 2018. Available from: DOI:10.1088/1742-6596/1090/1/012018.

[6] Lei G, Lope G, Tabil DW, Guanghui W. Influence of moisture content and hammer millscreen size on the physical quality of barley, oat, canola, and wheat straw briquettes. Biomass and Bioenergy. 2016; 94: 201-208.

[7] Demirbas ME. Current technologies for biomass conversion into chemicals and fuels. Energy Sources. 2006; 28(13): 1181-1188.

[8] Jindaporn J, Songchai W. Production and characterization of rice husk based charcoal briquette. KKU Engineering Journal. 2007; 34(4): 391-398.

[9] Abdillah AF, Sutrisno W. The potential of Casanova and rice husk waste as raw material for briquettes. JOIR. 2013; 12(2): 39-48.

[10] Reeb J, Milota M. Moisture content by the oven-dry method for industrial testing. Oregon State University. 1999. Available from: https://ir.library.oregonstate.edu/downloads/jm214q048.

[11] AOAC. Association of Official Analytical Chemistry. Official Methods of AOAC International. 14th Edition. Gaithersberg, MD, USA; 1990.

[12] Efomah AN, Gbabo A. The physical, proximate and ultimate analysis of rice husk briquettes produced from a vibratory block mould briquetting machine. IJISET-International Journal of Innovative Science, Engineering \& Technology. 2015; 2(5): 814-822.

[13] Wilaipon P. Density equation of bio-coal briquette and quantity of maize cob in Phitsanulok, Thailand. American Journal of Applied Sciences. 2008; 5(2): 1808-1811.

[14] Yerima I, Grema MZ. The potential of coconut shell as biofuel. The Journal of Middle East and North Africa Sciences. 2018; 4(8): 11-15.

[15] Pallavi HB, Srikantaswamy S, Kiran MB, Vyshnavi DR, Ashwin CA. Briquetting agricultural waste as an energy source. Journal of Environmental Science, Computer Science and Engineering \& Technology. 2013; (2)1: 160-172.

[16] Nazari MM, San CP, Atan NA. Combustion performance of biomass composite briquette from rice husk and banana residue. International Journal ON Advance Science Engineering Information Technology. 2019; 9(2): 455460.

[17] Huko D, Kamau DN, Ogola WO. Effects of varying particle size on mechanical and combustion characteristics of mango seed shell and cashew nut shell composite briquette. International Journal of Engineering Science 
Invention. 2015; 4(5): 32-39.

[18] Suryaningsih S, Nurhilal O, Yuliah Y, Salsabila E. Fabrication and characterization of rice husk charcoal bio briquettes. AIP Conference Proceedings. 2018; 1927(1). Available from: DOI: 10.1063/1.5021237.

[19] Zakari IY, Ismaila A, Sadiq U, Nasiru R. Investigation of addition of binder and particle size on the high calorific value of solid biofuel briquette. Journal of Natural Sciences Research. 2013; 3(12): 30-34.

[20] Arévalo J, Quispe G, Raymundo C. Sustainable energy model for the production of biomass briquettes based on rice husks in Peruvian low-income agricultural areas. Green Energy Advances. 2018; 1-19. Available from: http:// dx.doi.org/10.5772/intechopen.81817.

[21] Yuliah Y, Kartawidjaja M, Suryaningsih S, Ulfi K. Fabrication and characterization of rice husk and coconut shell charcoal based bio-briquettes as alternative energy source. International conference of biomass: Technology, Application and Sustainable development, IOP Publishing Conference Series: Earth and Environment Science. 2017; 65: 1-8. Available from: DOI: 10.1088/1755-1315/65/1/012021.

[22] Liang Q, Liu Y, Chen M, Ma L, Yang B, Li L, Liu Q. Optimized preparation of activated carbon from coconut shell and municipal sludge. Materials Chemistry and Physics. 2019; 241(1). Available from: https://doi.org/10.1016/ j.matchemphys.2019.122327.

[23] Menya E, Olupot PW, Storz H, Lubwama M, Kiros Y, John MJ. Optimization of pyrolysis conditions for char production from rice husks and its characterization as a precursor for production of activated carbon. Biomass Conv. Bioref. 2020; 10: 57-72. Available from: https://doi.org/10.1007/s13399-019-00399-0.

[24] Suman S, Gautam S. Physicochemical performance of wood chips char and wheat husk char for utilisation as an alternate source of energy. International Journal of Recent Technology and Engineering (IJRTE). 2020; 8(5): 22773878.

[25] Wazir AH, Wazir IU, Wazir AM. Preparation and characterization of rice husk based physical activated carbon. Energy Sources, Part A: Recovery, Utilization, and Environmental Effects. 2020. Available from: DOI: 10.1080/15567036.2020.1715512.

[26] Lionel S, Karunakaran RJ. A comparative study of two biochars based on the temperature of pyrolysis for phytoremediation of chromium spiked soil by Canna indica L. Journal of Pharmacognosy and Phytochemistry. 2017; 6(5): 104-111. 